\title{
Assessment of the Innovative Capacity of Intellectual Property
}

\section{Aleksandr Mikhaylovich Batkovskiy ${ }^{1}$}

Pavel Andreevich Kalachikhin²

\author{
Elena Georgievna Semenova ${ }^{3}$
}

\author{
Yury Filippovich Telnov²
}

\section{Alena Vladimirovna Fomina ${ }^{1}$}

\author{
1 Joint Stock Company "Central Research Institute of Economy, Management and Information Systems "Electronics", \\ Moscow, Russian Federation \\ 2 The Department of Applied Informatics in Economics, Moscow State University of Economics, Statistics and Informatics, \\ Moscow, Russian Federation \\ ${ }^{3}$ The Department of Innovation and Quality Management, St. Petersburg State University of Aerospace Instrumentation, \\ St. Petersburg, Russian Federation \\ Email: batkovskiy_a@instel.ru
}

\section{Doi:10.5901/mjss.2015.v6n4s4p325}

\section{Abstract}

This article is dedicated to development of methods for assessment of the intellectual property's innovative capacity based on the mathematical tools of fuzzy sets. It shows that the structure of the intellectual property's innovative capacity is determined by sets of factors affecting its formation and the criteria related to these factors. The structure of innovative capacity is represented by the following components: competitiveness, available resources, economic efficiency, feasibility and external investment risks. The indicator tree illustrates the structure of the intellectual property's innovative capacity. The multicomponent method of assessment of the intellectual property's innovative capacity implies application of basic methods for finding the components of the innovative capacity and objective function of components' consolidation. The author suggests to combine the components of the intellectual property's innovative capacity through fuzzification with subsequent reverse procedure of defuzzification. Fuzzification implies transformation of components of the core of the intellectual property's innovative capacity into linguistic variables using production rules of fuzzy logics, and external investment risks are fuzzificated by means of minimax functions. Defuzzification of components of the core of innovative capacity and external investment risks is defined by the functions with input parameters in the form of linguistic variables and fuzzy trapezoidal numbers. Use of these methods focuses on improvement in the approach to assessment of the potential economic efficiency of intellectual property in innovations. The article considers the opportunities for extension of the structure and modification of approaches to assessment of the intellectual property's innovative capacity. The author suggests to apply expert systems in management of the innovative capacity in various economic activities.

Keywords: innovations, innovative capacity, assessment, results, intellectual property, econometric model.

\section{Introduction}

Building an approach to assessment of the intellectual property's innovative capacity is important because a research and innovative organization receives an opportunity to define an innovation management strategy, to set priorities in management of innovative projects and to disclose available reserves based on estimations performed using such method. Building the above approach, we need to solve the issue of formalization of the structure of the intellectual property's innovative capacity in the form of an objectives tree. This allows to develop an approach to assessment of the intellectual property's innovative capacity with account for uncertainty, ambiguity and incompleteness of the input data and external conditions. Expert systems are suggested for making decisions regarding development of the intellectual capacity of research and innovative organizations.

The suggested approach to assessment of the intellectual property's innovative capacity takes into account marketing, corporate, financial and random factors in commercialization and capitalization of intellectual property by 
research and innovative organizations. Its elaboration required development of the theory in respect of economic agents' innovative capacity at the micro-level based on the estimated innovative capacity of intellectual property and application of fuzzy sets theory for its qualitative assessment under the conditions of uncertainty and incompleteness of input data.

The developed approach to assessment of the intellectual property's innovative potential may be applied in management of a research and innovative organization when solving such tasks as making investment decisions, setting priorities in allocation of resources among research projects, building portfolios of research projects and R\&D management.

Selection of structural elements and parameters for the approach to assessment of the intellectual property's innovative capacity is an issue which is open for discussion. That's why this approach was developed in such a way as to provide an opportunity for further modification or adaptation to specific features of various economic activities.

The research results are summarized in conclusions on the problem of assessment of the intellectual property's innovative capacity.

\section{Literature Review}

Innovative capacity research has a long history. Schumpeter and Hayek, an Austrian economist, created a model of the national innovations system, laying the foundation for further studies in the area of the macroeconomic systems' innovative capacity (Schumpeter, J.A.,1983; Schumpeter, J.A., 1994). Kondratyev, a Soviet economist, invented the "long cycles", which fit within the model of cyclical fluctuations of the macroeconomic system's innovative capacity. In the middle of $20^{\text {th }}$ century, Kantorovich, a Soviet economist, studied cooperation between research institutions and industry in economic planning; he focused on assessment of efficiency of technical innovations, which was much later applied in the theory of products' innovative capacity. Kantorovich's research was continued by Prigozhin in the second half of $20^{\text {th }}$ century, who studied the incentives and obstacles of innovative capacity realization. Starting from the middle of $20^{\text {th }}$ century and until present, a set of innovation models was built, with estimation of the innovative capacity of the national economy, its industries and companies. At the beginning of $21^{\text {st }}$ century, innovative capacity became not just an important component of the innovation management theory, but it is also used in solving of various economic tasks. Recent research trends include innovative networks (Araujo, T. and Mendes, R.), comprehensive product systems (Wang, S. and Wan, C., 2014), innovation diffusion (Goncavles, S. et al, 2012.) and technology transfer (Neelanjan, S., 2011), which are riddled with the ideas of the innovative capacity theory.

Innovative capacity was initially considered as a macroeconomic indicator of quite sophisticated systems being a part of the national innovative framework integrated with other economic institutions (Gayazova, D.V., 2012). This indicator included many subordinate types of capacity, each of which had its own approach to estimations. Later on, research efforts started to focus on the lower level objects (commercial and non-commercial enterprises). A link between the innovative capacity and marketing was discovered in enterprises' relationships with customers and requirements to the products. Research focus shifted to the essence of the innovative capacity, offering various models and methods of its assessment, ways of innovative capacity's utilization in management of economic systems; estimations were based on financial and statistical reports, and they were presented mostly in the form of tables (Kain, A. et al, 2010; Zizlavsky, O., 2011).

Detailed research was made in respect of the innovative capacity of organizations in general (Aletdinova, A.A., 2012; Kurach, A.E., 2011; Shapovalova, T.A., 2010), research institutions (Popova A.l., 2009) and research and production enterprises (Artemova, M.M., 2006). 'Economic capacity', or simply 'capacity' (being the focus of current research trends) comprises innovative, intellectual, commercial, resource, technological and other capacities of sophisticated and fast growing systems. These issues are important for economics, since they are directly related to modeling of the market economy's macroeconomic development.

'Innovative capacity' may be interpreted differently by different authors, depending on the study area and application. 'Innovative capacity' is generally used for commercial organizations, which may include production facilities in different industries. This term is also used in respect of territories (cities, regions, states) and economic complexes (branches, production facilities). However, classification of innovative capacities (Mirzabekova, M. Ju., 2013) admits existence of a product-related innovative capacity, established for specific products or services. We should mention that innovative capacities of research projects and intellectual property did not receive detailed consideration in research literature before.

Oslo Manual (Oslo Manual, 2010) defines company's innovative capacity as the company's ability to enjoy market advantages as a result of its accumulated knowledge, human resources, procedures, routine practices. Matveykin (Matveykin V.G. et al., 2007) interprets 'innovative capacity' as the system's capacity to transform the existing condition 
into a new condition in order to satisfy existing or emerging needs. Besides, innovative capacity describes the system's readiness for changes, improvements and progress. According to Dezhkina (Dezhkina, I.P. and Potasheva, G.A., 2001), innovative capacity is an aggregate capacity of a production organization and the management structure's capacity, as well as a set of production, labor, market, resource, intellectual, research, technological, investment, strategic capacities. Zharikov (Zharikov, V.V. et al., 2009) considers innovative capacity (at the national, industry or company levels) as a set of different types of resources, including material, production, financial, intellectual, research, technological and other resources required for innovations.

Based on the above definitions, it does make sense to consider the intellectual property's innovative capacity as a complex economic indicator, which describes the potential economic effect from innovations created on the basis of this intellectual property. In such case, innovations become strongly connected with creation of intellectual property, i.e. generation of new knowledge.

Approaches to assessment of innovative capacity are developed independently for each class of objects; no integrated methodological approach exists. The resource factor, as well as the organizational, functional and personal factors are considered as the main factors of innovative capacity (Abramov, V.I., 2012). The innovative capacity of the economy significantly affects relevant capacities at the regional level; in turn, regional innovative capacities affect the capacities of organizations located therein, which in some way connects innovation capacities at different levels. Vertical hierarchy of innovative capacity descends from the macro-level (global and national economies) via the meso-level (industries and regions) down to the micro-level (enterprises). Upper and lower sub-micro levels focus on research projects and intellectual property.

Based on the presented analysis of studies dedicated to assessment of innovative capacity, we may conclude on the need for further research focusing on application by research and innovative organizations of relevant approaches to intellectual property.

\section{Methods}

\subsection{The study of the intellectual property's innovative capacity included the following phases:}

a) building the econometric model of the intellectual property's innovative capacity:

1) identification of the key factors and criteria of innovative capacity assessment;

2) identification of the structure of innovative capacity;

3) selection of basic methods for estimation of innovative capacity's components;

4) identification of restrictions imposed on innovative capacity's components;

5) description of applications of the econometric model for the intellectual property's innovative capacity;

6) development of an approach to assessment of the intellectual property's innovative capacity: 1) formalization of the method of consolidation of innovative capacity's components; 2) estimation of significance of innovative capacity's components; 3) estimation of the range of the innovative capacity.

Implementation of such approach allowed to shift from the econometric models in analysis of the innovative capacity's components to specific methods of their assessment, and from the general econometric model of the intellectual property's innovative capacity to specific methods of its assessment.

\subsection{Research methods}

Our research involved structural, factor and comparative analysis, as well as formalization and modeling methods. The innovative capacity of intellectual property is examined using the structural and component approaches. Analysis is based on the hypothetico-deductive method. The innovative capacity of intellectual property is specified by a set of variables and parameters. They are selected and systematized by means of methods of factor and structural analysis. Factor analysis allows to consider dependence of the object's condition on the factors which affect it. Factor study is used for identification of the components of the intellectual property's innovative capacity from the list of key factors and criteria. Structural analysis focuses on identification of internal relationships between the components of the whole object. Such comparison allows to identify the object-specific structural elements. This type of analysis is used to determine the innovative capacity's structure for different types of intellectual property. Application of the deductive approach may be justified by existing common patterns, external conditions, factors and criteria, which should be used in building of relevant approaches to assessment of intellectual property's innovative capacity and development of other procedures. 


\subsection{Mathematical tools}

The research method was based on special mathematical tools: expert opinions for qualitative analysis, rating models for ranking based on a set of criteria, analytical indicators for development of indicators, probability theory for risk assessment, fuzzy logics for dealing with uncertainties, fuzzy sets for consolidation of indicators. Expert methods are used for assessment of qualitative characteristics of intellectual property, which are hard to measure quantitatively, as well as for assessment of possible risks, probabilities and damage, which can not be estimated using strict formulae. The rating model allows to make the integral qualitative assessment of characteristics of the intellectual property on the basis of expert opinions, which is transformed to the required type depending on the selected model parameters. Measurable indicators are estimated analytically as weighted values. Apart from expert methods, risks are assessed based on fundamental laws of the probability theory. The fuzzy sets theory and fuzzy logics are in the core of the applied mathematical tools.

\section{Results}

Assessment of the intellectual property's innovative capacity is formalized by means of the following sets:

1. Structure $(S)$ of the intellectual property's innovative capacity, which is the system of indicators forming the assessment of the intellectual property's innovative capacity: $S(I)$ means the structure of the intellectual property's innovative capacity;

2. Criteria of innovative capacity ( $C=\left\{c_{\kappa}\right\}$ ) mean the terms, ways, signs of achievement by innovative capacity of its target level, which allow quantifications, known as factor indicators and indicators, which are based on these criteria;

3. Innovative capacity factors ( $F=\left\{f_{l}\right\}$ ) mean the general characteristics of innovative capacity, which determine its nature and certain characteristics affecting its level. When estimating the intellectual property's innovative capacity, we need to take into account a large quantity of factors. According to the multifactor

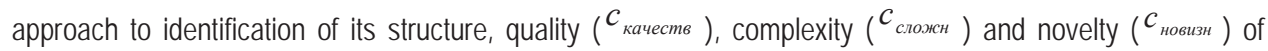
intellectual property belong to marketing factors $\left(f_{\text {mapk }}\right)$; ability to make arrangements for development of intellectual property using the required resources $\left({ }^{c}\right.$ pec $)$ is a corporate factor $\left(f_{\text {кopn }}\right)$; $\operatorname{costs}\left({ }^{c_{\text {заmpam }}}\right)$, market price $\left({ }^{c_{\text {иен }}}\right.$ ), expected revenue ( ${ }^{c_{\text {доход }}}$ ) and projected profit $\left({ }^{c_{\text {приб }}}\right.$ ) are considered as financial factors ( $f_{\text {фин }}$ ); risks $\left({ }^{c_{\text {рuск }}}\right.$ ) represent random factor $\left(f_{\text {cryu }}\right)$. The multifactor approach allows to describe the intellectual property's innovative capacity from various perspectives, which provides a more comprehensive view and creates the preconditions for utilization of the component-based approach when determining the structure of the intellectual property's innovative capacity.

Therefore, the lower level indicators and components, which define the structure of the intellectual property's innovative capacity, are deduced from the factors and assessment criteria of the intellectual property's innovative capacity:

$$
\{C, F\} \rightarrow S \text {, }
$$

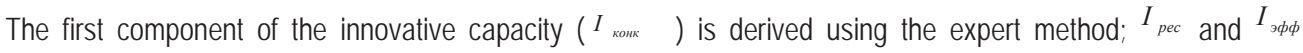
components are derived using the indicator method; expert risk assessments are used for finding $I_{y c n e x}, Q_{P C}$, $Q_{P P}$ and $Q_{P O}$ components:

$$
S(I)=\left\{I_{\text {конк }}, I_{\text {рес }}, I_{\text {эфф }}, I_{\text {успех }}, Q_{P C}, Q_{P P}, Q_{P O}\right\} \text {, }
$$

Indicators in equation (2) provide the most adequate representation of the structure of the intellectual property's innovative capacity, its internal, resource and resultant components. These are, respectively, competitiveness ( $\left.I_{\text {конк }}\right)$, available resources $\left({ }^{I}\right.$ pec $)$, economic efficiency $\left({ }^{I_{\text {}}}{ }\right.$ ) $)$ and feasibility of intellectual property $\left({ }^{I_{\text {ycnex }}}\right)$, as well as external investment risks $\left(Q_{P C}, Q_{P P}, Q_{P O}\right)$ which result from the adverse affect of the investment climate in the country, region and industry.

The intellectual property's innovative capacity has three assessment levels: integrated characteristic at the upper 
level, the medium level of components, the lower level of primary indicators. The intellectual property's innovative capacity is estimated towards consolidation of the primary indicators. First of all, indicators and factors are estimated and designated as primary indicators of the intellectual property's innovative capacity. Then, components of the intellectual property's innovative capacity are formed out of the primary indicators. The integrated assessment of the intellectual property's innovative capacity is derived from the values of its components at the final step.

Figure 1 shows the structure of the intellectual property's innovative capacity in the form of an indicators tree.

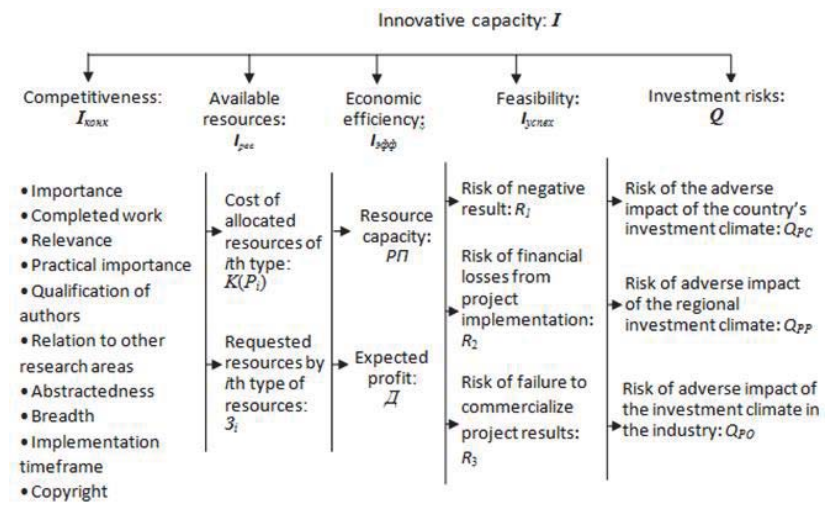

Figure 1. Indicators tree of the intellectual property's innovative capacity

Innovative capacity's structure is not fixed in formula (2). This means that we may eliminate some components from the structure or add new components in estimating the intellectual property's innovative capacity. The component structure is affected by the type of intellectual property and available input data. The structure of the intellectual property's innovative capacity is expanded by adding new components, primary indicators, types of risks, rating model criteria, resources. Structure's expansion should be accompanied with development of approaches to estimation of new components, so that new components could be combined with the set components. The structure of the components of the intellectual property's innovative capacity is set when assessed by a bit array $\left({ }^{B_{N}}\right)$. Bit array elements $\left({ }^{B_{N}}\right)$ are estimated by means of characteristic function:

$$
\begin{aligned}
& B_{N}=\left\{\Delta_{s^{*}}\left(Y_{i}\right)\right\}, \\
& \Delta_{S^{*}}\left(Y_{i}\right)=\left\{\begin{array}{lll}
1, & \text { if } & Y_{i} \in S^{*} \\
0, & \text { if } & Y_{i} \notin S^{*}
\end{array}\right.
\end{aligned}
$$

where ${ }^{Y_{i}}$ means $i_{\text {th }}$ component of the intellectual property's innovative capacity,

$i=\overline{1 \ldots N}, N=|S|, S^{*} \subseteq S, S^{*} \neq \varnothing$.

Therefore, $\left\{S, B_{N}\right\}$ sets or $S^{*}$ set may be given when estimating the intellectual property's innovative capacity. The multi-component structure of the intellectual property's innovative capacity is flexible and expandable. Flexibility of the intellectual property's innovative capacity compensates insufficiency of input data and allows to eliminate some components from the estimate. Assessment of the intellectual property's innovative capacity reflects the expected effect from commercialization of acquired and independently elaborated intellectual property. The intellectual property's innovative capacity has several components, each of which corresponds to one component of the innovative capacity. The multi-component approach (which is based on mathematical tools of fuzzy sets) uses the following formula for assessment of the intellectual property's innovative capacity:

$$
I=\frac{\varphi(\|\hat{I}\|)}{\phi(\breve{Q})},
$$

where $\hat{I}$ is the so called 'core' of the intellectual property's innovative capacity; $\breve{Q}$ is the integrated external investment risk of the intellectual property's innovative capacity; $\varphi$ is the defuzzification function of linguistic variables; $\phi$ is the defuzzification function of fuzzy trapezoidal numbers; \|\| means normalization of linguistic variables. 
We suggest to use a linguistic variable for typification of the core of the intellectual property's innovative capacity, and trapezoidal fuzzy number for typification of integrated external risks. Linguistic and trapezoidal fuzzy types of the numerator and denominator in formula (5) allow to assess the intellectual property's innovative capacity under the conditions of uncertainty, incompleteness or deficit of input data and conflicts between the values of components of the intellectual property's innovative capacity. Particularly, the core of the intellectual property's innovative capacity is assessed in the form of a linguistic variable:

$$
\hat{I}=\left\{\text { Very low } \mathrm{CF}_{1} ; \text { Low } \mathrm{CF}_{2} ; \text { Medium } \mathrm{CF}_{3} ; \text { High } \mathrm{CF}_{4}\right\} \text {, }
$$

with $\mathrm{CF}_{1}, \mathrm{CF}_{2}, \mathrm{CF}_{3}, \mathrm{CF}_{4}$ confidence factors, defined by membership functions.

The structure of the core of the intellectual property's innovative capacity of a random type consists of four components. After fuzzification, the linguistic components of the core of the intellectual property's innovative capacity are combined using the formula for addition of fuzzy numbers:

$$
\hat{I}=\hat{I}_{\text {конк }}+\hat{I}_{\text {рес }}+\hat{I}_{\text {эфф }}+\hat{I}_{\text {yспех }} \text {, }
$$

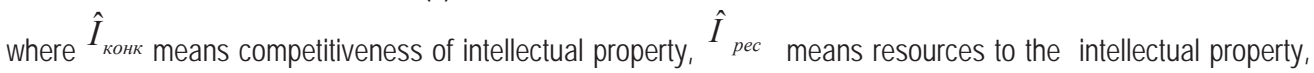
$\hat{I}_{{ }_{э \phi \phi}}$ means economic efficiency of intellectual property, $\hat{I}_{y c n e x}$ means feasibility of intellectual property.

Therefore, assessment of the core of the intellectual property's innovative capacity is expressed through competitiveness, available resources, economic efficiency and feasibility of intellectual property. Figure 2 shows the graph of the fuzzy set membership functions of the core components of the intellectual property's innovative capacity. Experts selected increasing and decreasing linear functions as membership functions; therefore, the fuzzy set membership functions of the innovative capacity have triangular form.

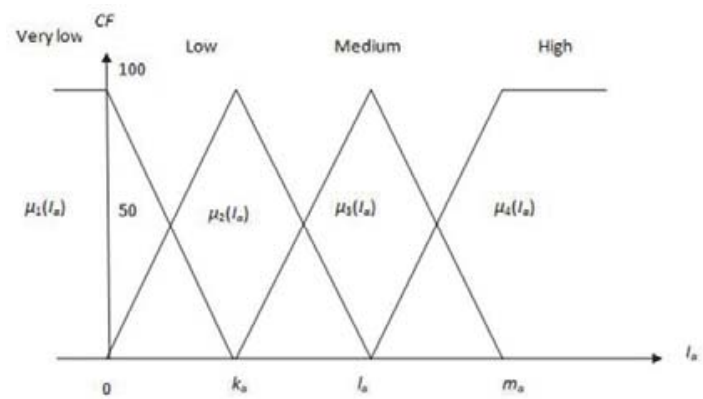

Figure 2. Fuzzy set membership functions of the intellectual property's innovative capacity

In accordance with production rules, estimated value $I_{\alpha}$ of a component of the core of the intellectual property's innovative capacity under number $\alpha$, where $\alpha \in\{$ конк, рес, эфф, успех $\}$, image into linguistic variable $\hat{I}_{\alpha}$ :

1. IF $I_{\alpha}=0$, THEN $^{\hat{I}_{\alpha}}=$ "Very Low" CF 100 ;

2. IF $I_{\alpha}>0 \wedge I_{\alpha}<k_{\alpha}$;

THEN\{ "Very Low" CF $\mu_{1}\left(I_{\alpha}\right)$, "Low" CF $\left.\mu_{2}\left(I_{\alpha}\right)\right\}$;

3. IF $I_{\alpha} \geq k_{\alpha} \wedge I_{\alpha}<l_{\alpha}$;

THEN $\left\{\right.$ "Low" CF $\mu_{2}\left(I_{\alpha}\right)$, "Medium" CF $\left.\mu_{3}\left(I_{\alpha}\right)\right\}$;

4. $\mathrm{IF} I_{\alpha} \geq l_{\alpha} \wedge I_{\alpha}<m_{\alpha}$;

THEN $\left\{\right.$ "Medium" CF $\mu_{3}\left(I_{\alpha}\right)$, "High" CF $\left.\mu_{4}\left(I_{\alpha}\right)\right\}$;

5. IF $I_{\alpha} \geq m_{\alpha}$, THEN $\hat{I}_{\alpha}=$ "High" CF 100 .

Membership functions are set by the following formulae: 


$$
\begin{aligned}
& \mu_{1}=\left\{\begin{array}{l}
I_{\alpha} \in(-\infty ; 0], c f=100 \\
I_{\alpha} \in\left[0 ; k_{\alpha}\right], c f=100-I_{\alpha} \cdot \frac{100}{k_{\alpha}},
\end{array}\right. \\
& \mu_{2}=\left\{\begin{array}{l}
I_{\alpha} \in\left[0 ; k_{\alpha}\right], c f=I_{\alpha} \cdot \frac{100}{k_{\alpha}} \\
I_{\alpha} \in\left[k_{\alpha} ; l_{\alpha}\right], \\
c f=100-\frac{100}{l_{\alpha}-k_{\alpha}} \cdot\left(I_{\alpha}-k_{\alpha}\right)
\end{array},\right. \\
& \mu_{3}=\left\{\begin{array}{l}
I_{\alpha} \in\left[k_{\alpha} ; l_{\alpha}\right], c f=\frac{100}{l_{\alpha}-k_{\alpha}} \cdot\left(I_{\alpha}-k_{\alpha}\right) \\
I_{\alpha} \in\left[l_{\alpha} ; m_{\alpha}\right], \\
c f=100-\frac{100}{m_{\alpha}-l_{\alpha}} \cdot\left(I_{\alpha}-l_{\alpha}\right)
\end{array},\right. \\
& \mu_{4}=\left\{\begin{array}{l}
I_{\alpha} \in\left[l_{\alpha} ; m_{\alpha}\right], c f=\frac{100}{m_{\alpha}-l_{\alpha}} \cdot\left(I_{\alpha}-l_{\alpha}\right) \\
I_{\alpha} \in\left[m_{\alpha} ; \infty\right), c f=100
\end{array},\right.
\end{aligned}
$$

$k_{\alpha}, l_{\alpha}, m_{\alpha}$ values are the model parameters and interval boundaries for the component under index $\alpha$. Model parameters for a certain set of intellectual property are determined by an expert depending on the level of strictness of requirements to the intellectual property's innovative capacity.

The fuzzy sets theory eliminates conflicts between the values of primary indicators when estimating the intellectual property's innovative capacity, and operations with linguistic variables consolidate the components of the core of the intellectual property's innovative capacity. In turn, application of the fuzzy logics' production rules helps to transform the numerical components of the intellectual property's innovative capacity into the fuzzy form (Telnov, Yu.F. and Kalachikhin, P.A., 2014). Intellectual property's competitiveness is assessed based on the rating method. Intellectual property's competitiveness is estimated using the following formula:

$$
I_{\text {конк }}=\frac{\sum_{i=1}^{M} E x_{i}}{M} \text {, }
$$

where $E x_{i}$ is the overall estimate of intellectual property by one expert $\left({ }^{0 \leq E x_{i}} \leq 1\right) ; M$ is the quantity of experts participating in assessment.

Resources available to intellectual property are estimated in accordance with formula (13):

$$
I_{p e c}=\sqrt[n]{\prod_{i=1}^{n} \frac{K\left(P_{i}\right)}{3_{i}}}
$$

where $K\left(P_{i}\right)$ is the monetary value of dedicated resource of $i$ th type; ${ }^{3}$ means total costs for development of intellectual property for ith type of resources.

We suggest to estimate the economic efficiency of the intellectual property as one of the components of intellectual property's innovative capacity, based on the ratio of expected profit $({ })$ from the intellectual property's commercialization to its resource capacity $(P \Pi)$ :

$$
I_{э \phi \phi}=\frac{Д}{P \Pi},
$$

where $Д$ is the expected profit; $P \Pi$ means resource capacity.

Intellectual property's resource capacity $(P \Pi)$ is equal to the total cost of all other types of resources grouped by their types and expressed in monetary form:

$$
P \Pi=\sum_{i=1}^{N} K\left(P_{i}\right)
$$

where summation is made in respect of resource types ${ }^{P_{i}}$ and $N=4$.

Selection of formula for assessment of the expected profit depends on the type of intellectual property. 
The expected profit from a marketable intellectual property is determined as the discounted difference of sales revenue and related costs:

$$
Д=\sum_{t=1}^{T}\left[\left(s \cdot V_{t} \cdot \frac{(d+1) \cdot P V+L_{t}^{0} \cdot \prod_{j=1}^{n} a_{j}}{2}-3_{t}^{c o s}-3_{t}^{\text {доs }}-3_{t}^{\text {pez }}-3_{t}^{y n}-3_{t}^{\text {мap }}\right) \cdot(1+r)^{-T}\right],
$$

where $T$ is the quantity of estimation periods during the phase of commercialization of the intellectual property's life cycle; $S$ means the percentage of payments for transfer of user rights for each intellectual property; $V_{t}$ is the amount of intellectual property during period $t ; P V$ is the cost of reproduction of one copy of intellectual property; $d$ is the markup parameter; $L_{t}^{0}$ means the sale price of similar intellectual property during period $t ; a_{1}, a_{2}, \ldots a_{n}$ mean adjustment factors related to the characteristics of quality, complexity and novelty of intellectual property as compared to the similar intellectual property, assessed by experts based on the 'less-more' scale; ${ }_{t}^{\text {cos }}$ means the intellectual property creation costs; ${ }_{t}^{3_{t}^{\text {дов }}}$ means the costs of completion of the intellectual property; ${ }_{t}^{\text {pez }}$ means intellectual property registration costs; ${ }^{3 n}$ means intellectual property improvement costs; ${ }_{t}^{\text {марк }}$ means marketing costs; $r$ means price growth.

The economic effect of production and technological intellectual property is expressed in change in sales of future products, development and growth of related activities. However, it does not seem possible to include real sales of products into assessment of the innovative capacity referred to the initial phase of innovation' life cycle, for which reason products and services should be considered as planned production volumes involving intellectual property.

If innovation is produced by only one intellectual property, on the basis of which only one type of products is made, then the expected profit will be calculated as the discounted difference between revenues and costs:

$$
\text { Д }=\sum_{t=1}^{T}\left[V_{t}^{*} \cdot\left(L_{t}-3_{t}\right)\right] \cdot(1+r)^{-T} \text {, }
$$

where $V_{t}^{*}$ means the volume of production involving intellectual property; $L_{t}$ is the unit price; ${ }^{3}$ means unit production costs; $r$ is the discount rate; $T$ is the quantity of estimation periods.

Product unit price is found as a marketing characteristic of similar products:

$$
Ц=\prod_{j=1}^{n} a_{j} \cdot Ц_{0}
$$

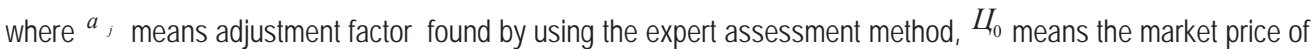
a similar product.

Production volume is limited by the equipment's capacity. Equipment capacity is set by the planned characteristics of capacity which are improved by intellectual property:

$V^{*}=V \cdot K, \quad(19)$

where $V$ is the production volume; $K$ is the increasing or decreasing factor of change in production volume.

Factor $K$ may be found by using the following formula:

$$
K=I_{\text {конк }}+K_{0},(20)
$$

where $K_{0}=0,5$.

The expected profit generated by non-production intellectual property is found as follows:

Д $=Ц V \cdot V-3_{0}$,

where $U$ is the market price of non-production intellectual property; $V$ means sales of non-production intellectual property; ${ }^{3}$ means the costs of production of the initial version of intellectual property, which is copied when sold.

Let's consider the intellectual property's feasibility ( ${ }^{I_{\text {yonex }}}$ component).

Assessment of intellectual property's innovative capacity includes assessment of risks emerging from uncertainty of final results of research project and unpredictability of the research and innovation environment. Creation of intellectual property is described by three main types of risks:

- achievement of negative result $\left(R_{1}\right)$; 
- loss of invested money $\left({ }^{R_{2}}\right)$;

- adverse economic effect from implementation $\left(R_{3}\right)$.

The total risk depends on the probability of risk occurrence and potential loss. Risk indicators are found by way of expert assessment: an expert would assess the probability of risk occurrence and the damage factor (risk level). Risk probability is expressed with numbers from zero to one; risk level is scaled from small to catastrophic risk (Table 1).

Table 1. Scale of project risks of implementation of intellectual property

\begin{tabular}{lll}
\hline Risk type & Threat posed by risk $\left(w_{i}\right)$ & Risk probability $\left(R_{i}\right)$ \\
\hline 1. Achievement of negative result & - maximum $(0.999)$ & - very high $(0.99)$ \\
\hline 2. Financial losses from project implementation & - catastrophic $(0.875)$ & - high $(0.75)$ \\
& - large $(0.625)$ & - medium $(0.50)$ \\
3. Impossibility of commercialization of project results & - medium $(0.375)$ & - small $(0.25)$ \\
& - small $(0.125)$ & - insignificant $(0.01)$ \\
\hline
\end{tabular}

Feasibility $\left({ }^{I_{\text {cnex }}}\right)$ equals to:

$$
I_{\text {ycnex }}=1-P=1-\frac{\sum_{i=1}^{3}\left(w_{i} \cdot R_{i}\right)}{\sum_{i=1}^{3} w_{i}},
$$

where $P$ is the integral estimate of project risks; $R_{i}$ means probability of $i_{\text {th }}$ risk; $w_{i}$ is the level of $i$ th risk determined by scale; $N=3$.

The values of core components of the intellectual property's innovative capacity are limited as follows:

$$
\left\{\begin{array}{l}
0 \leq I_{\text {конк }} \leq 1, \\
I_{\text {рес }} \geq 0, \\
I_{\text {эфф }} \geq 0, \\
0 \leq I_{\text {успех }} \leq 1 .
\end{array}\right.
$$

Defuzzification function $\varphi$ of the intellectual property's innovative capacity $\hat{I}$ is set by the following expression:

$$
\varphi(\hat{I})=\frac{1}{2}-\frac{C F_{1}}{300}-\frac{C F_{2}}{600}+\frac{C F_{3}}{600}+\frac{C F_{4}}{300} \text {. }
$$

Since the core of the intellectual property's innovative capacity has a linguistic variable type, limitation is imposed on the total quantity of intellectual property involved in research projects and the total quantity of projects, for which the innovative capacity can not be reliably interpreted.

The limitation is explained by the fact that (in case of several components) assessments of certain components do not always conform with each other, and consolidation of components may sometimes result in high confidence factors with several scales. Confidence factors of the core values of the intellectual property's innovative capacity should be normalized in order to avoid non-conformity. Normalizing of the intellectual property's innovative capacity \|\| is established by the following formula:

$$
\begin{gathered}
\|\left\{\text { "Very low" } \mathrm{CF}_{1}, \text { "Low" } \mathrm{CF}_{2} \text {, "Medium"CF} 3, \text { "High" } \mathrm{CF}_{4}\right\} \|= \\
=\left\{\begin{array}{l}
\text { "Very Low" } 100 \cdot C F_{1} / \sum_{1}^{4} C F_{i}, \text { "Low" } 100 \cdot C F_{2} / \sum_{1}^{4} C F_{i}, \\
\text { "Medium" } 100 \cdot C F_{3} / \sum_{1}^{4} C F_{i}, \text { "High" } 100 \cdot C F_{4} / \sum_{1}^{4} C F_{i}
\end{array}\right\},
\end{gathered}
$$

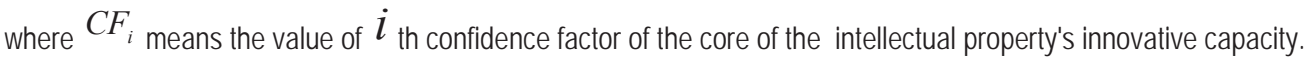

Integrated transformed assessment $J$ of the subset of components of the innovative capacity $(I)$ of intellectual property is found by formula (26): 


$$
J=\varphi(\|\hat{I}\|)=\varphi\left(\left\|\hat{I}_{\text {конк }}+\hat{I}_{\text {рес }}+\hat{I}_{\text {эфф }}+\hat{I}_{\text {успех }}\right\|\right) .
$$

Three types of external investment risks exist for intellectual property:

- adverse impact of the country's investment climate $\left({ }^{Q_{P C}}\right)$;

- adverse impact of the regional investment climate $\left(Q_{P P}\right)$;

- adverse impact of the industry's investment climate ( $Q_{P O}$ ).

Foreign trade, force majeure, market, foreign exchange and other types of risks are not taken into account, since they mostly affect commercial operations rather than research. External investment risks are found by experts:

$$
Q_{\alpha}=\frac{\sum_{j=1}^{M} Q_{\alpha}^{j}}{M}=\frac{\sum_{j=1}^{M} w_{\alpha}^{j} \cdot q_{\alpha}^{j}}{M},
$$

where $Q_{\alpha}^{j}$ means assessment of an external risk under index $\alpha$ by $j_{\text {th }}$ expert; $q_{\alpha}^{j}$ means the probability of emergence of external risk under index $\alpha$, set by ${ }^{j}$ th expert, $q_{\alpha}^{j} \in(0,1) ; w_{\alpha}^{j}$ means the level of risk under index $\alpha$, set by ${ }^{j}$ th expert, $w_{\alpha}^{j} \in(0,1) ; M$ is the quantity of experts; $\alpha \in\{P C, P P, P O\}$.

Let's assign a fuzzy number with trapezoidal membership function to each external investment risk:

$Q \rightarrow \breve{Q}$

Fuzzy number $\breve{A}$ is set by parameters $<a, b, \alpha, \beta>$.

Fuzzy addition or fuzzy multiplication operations are used for consolidation of external investment risks. Let's define addition and multiplication operations as follows:

$$
\begin{aligned}
& \breve{A}+\breve{B}=<a, b, \alpha, \beta>=<a_{1}+a_{2}, b_{1}+b_{2}, \alpha_{1}+\alpha_{2}, \beta_{1}+\beta_{2}>,(29) \\
& \breve{A} \cdot \breve{B}=<a, b, \alpha, \beta>=<a_{1} \cdot a_{2}, b_{1} \cdot b_{2}, a_{2} \cdot \alpha_{1}+a_{1} \cdot \alpha_{2}, b_{1} \cdot \beta_{1}+b_{2} \cdot \beta_{2}>.
\end{aligned}
$$

In such case, the integrated external investment risk is found by using the following formula:

$\breve{Q}=\breve{Q}_{P C} \cdot \breve{Q}_{P P} \cdot \breve{Q}_{P O}$. (31)

Formula (28) uses fuzzification diagram shown in Figure 3 :

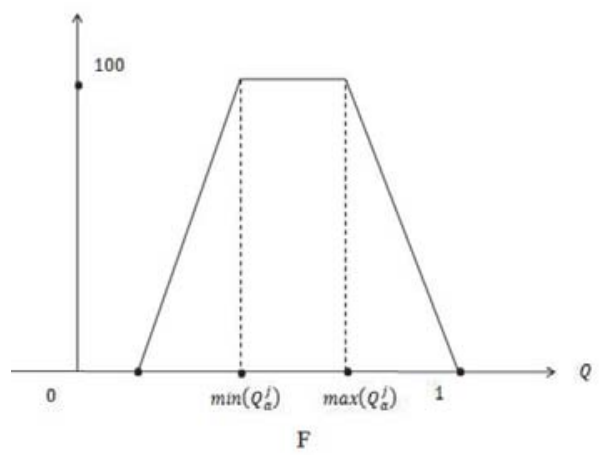

Figure 3. Fuzzification of external investment risks

Defuzzification function $\varphi$ of fuzzy trapezoidal number $\breve{X}=\langle a, b, \alpha, \beta\rangle$ is set as follows:

$$
\varphi(\breve{X})=\frac{\int_{a-\alpha}^{b+\beta} X \cdot \mu(X) d X}{\int_{a-\alpha}^{b+\beta} \mu(X) d X},
$$

where $\mu(X)$ is the fuzzy value membership function $\breve{X} ; X$ is the range of fuzzy value $\breve{X}$.

Components of external investment risks are imposed with the following limits: 


$$
\left\{\begin{array}{l}
0<Q_{P C} \leq 1, \\
0<Q_{P P} \leq 1, \\
0<Q_{P O} \leq 1 .
\end{array}\right.
$$

The developed approach to assessment of the intellectual property's innovative capacity has important practical application, which allows to manage research and innovative organization, as well as to solve related tasks, including interpretation, optimization, aggregation of the intellectual property's innovative capacity.

Therefore, the suggested approach to assessment of the intellectual property's innovative capacity allows to:

1. Estimate the intellectual property's qualitative characteristics using expert assessment method and consolidate them with the components obtained by using the indicator-based method;

2. Estimate the intellectual property's innovative capacity under the conditions of uncertainty and with incomplete input data;

3. Adjust to the type of relevant intellectual property, using any of three possible types as a parameter for selection of the formula for assessment of the intellectual property's economic efficiency;

4. Change the structure of the intellectual property's innovative capacity by eliminating or adding new components;

5. Expand the intellectual property's innovative capacity with new components using individual estimation approaches.

\section{Discussion}

The approach to assessment of the intellectual property's innovative capacity may be modified or adapted. For example, risks may increase or decrease, some factor indicators of the rating model may be assigned with negative weights, or another procedure for external investment risks fuzzification may be used. With such changes, the approach to assessment of the intellectual property's innovative capacity will not lose its benefits and will be improved.

The structure of the intellectual property's innovative capacity may be expanded by adding new components subject to the specific nature of the selected type of economic activity. Examples of new components may include possibility to replicate the intellectual property, popularity and demand, focus on short-term or long-term demand etc.

The intellectual property's foundation (which is the reason or the source of its creation) includes ideas which emerge in research and which are freely exchangeable by researches; in many cases, such ideas result from cooperation. Although in practice some balance exists between the creative and imperative components in the intellectual property creation process, it is difficult to determine the idea's value. That's why, the monetary value of the intellectual property should be based on its intrinsic value rather than on the costs of its creation.

Economic efficiency of the intellectual property's innovative capacity depends not only on the total costs of innovative property's creation, but also on its intrinsic value, which changes from time to time. With high rates of technological progress, the intrinsic value of intellectual property decreases as it loses its importance, but in some cases the reverse effect may be observed. This affects changes in economic efficiency on various phases of intellectual property's life cycle. It is quite difficult to obtain reliable and accurate estimates of innovation's efficiency through profitability, because this requires to specify the innovation's life cycle, which depends on the moment of emergence of a more state-of-the-art innovation (which is a hardly predictable indicator).

It is also difficult to estimate the contribution of intellectual property, which is used indirectly or which is freely distributable with free access, to innovations. The most sophisticated innovations are created from a few intellectual properties. In such case, consolidation of several intellectual properties provides a synergistic effect.

Some intellectual properties (including non-commercial intellectual properties) are not intended for implementation as part of innovations. Innovative capacity is not set for such intellectual properties; therefore, economic efficiency should be eliminated from the bit array.

Competitiveness (which is another component) is assessed when an application goes through a competition. The competition phase may not exist in the life cycle, in which case the competitiveness component should be also excluded from the innovative capacity's structure. This happens when rights are transferred or when finished intellectual property is sold.

Innovative capacity may be assessed both during the competitive selection, or during and upon completion of research. The degree of completeness affects the intellectual property's innovative capacity, since in the latter case the impact of project risks on feasibility of the intellectual property is not taken into account. Therefore, the suggested approach to assessment of the intellectual property's innovative capacity should be adapted to specific features of 
intellectual property.

The innovative capacity used to be considered as a fixed indicator assessed during the early phase of the innovation process. However, the innovative capacity does not emerge at the time of assessment - instead, it accumulates during R\&D; it does not disappear, but develops into a result - innovation, which would have some commercial success. Therefore, the innovative capacity is replaced with the function known as 'dynamic innovative capacity'.

According to the accepted classification, intellectual property is divided into the following three types: marketable, engineering and manufacturing, non-production. However, there may be any combinations of intellectual property and innovation types, created with the use thereof (Oluwoye, J. and Lenard, D., 1999).

Oslo Manual specifies four types of innovations: product (Ren, Y.-T. and Yeo, K.-T., 2006), process (Abernathy, W.J. and Utterback, J.M., 1978), organization (Henderson, R.M. and Clark, K.B., 1990) and marketing. It is not always possible to draw exact limits between different types of innovations; therefore, existing classification should be supplemented by the mixed type of innovations from all possible combinations of the existing four types. Then the innovations of the set mixed type would derive from the intellectual property of various types.

Innovative capacity is significantly affected by the economic climate and investment risks (Rogers, M., 2000), which are driven by external conditions; therefore, the intellectual property's innovative capacity depends on the external environment. Let's assume that intellectual property is completed in time and when the need for its creation is the most urgent. The intellectual property can not be $100 \%$ duplicated, and it is protected from illegal copying with copyright. This assumption holds starting from relatively recent moment when the 'intellectual property' term appeared in economic literature. Then the approach to assessment of the intellectual property's innovative capacity may be used only in a developed (in information and technological respects) market economy (Sen, N., 2011), i.e. the so called 'innovative economy' or 'knowledge economy'.

In addition to the innovative capacity, intellectual property may also have intellectual, information and other capacities. That's why, in order to avoid confusion, we need to describe (in an unambiguous manner) the vertical hierarchy of innovative capacity types, starting from the lower micro-level and ending by the upper macro-level. This is a challenging task, because there may be a large quantity of such segments, as hierarchy is divided into many elements. Each type of economic agents must be assigned its own element of the vertical hierarchy, provided that the quantity of various economic agents is extremely high and always growing. That's why, the innovative capacity should be linked to other types of capacities, shifting from comprehensive economic indicators to strategies, objectives, tasks, measures, decisions etc. This procedure comprises 'tuning' and 'adjustment' of practical application of approaches to assessment of the intellectual property's innovative capacity.

Some projects may be consolidated into 'megaprojects'. For example, research projects may be consolidated into comprehensive research programs, and innovative projects may be consolidated into state programs of industrial development. In such case, intellectual property may be consolidated into technologies, standards and other sophisticated tree structures, which change over time and do not always have expressly set elements and limits. Let's call such objects as 'megaresults'. The hypothesis of strong dependence of megaresults' efficiency on innovative capacity of megaprojects is formulated by analogy with the objects of smaller scale, provided that it is important to aggregate research projects and innovative projects into megaprojects and megaresults correctly.

Any research project may be suspended at some phase, and then continued. In such case, investment risks need to be revised. Factor indicators of relevancy, novelty etc. also need to be revised. Revision is also required for certain parameters involved in estimation of economic efficiency - market characteristics in comparison with analogue etc. After resumption, the innovative capacity should not be lower than the initial one; otherwise there is no sense to continue operations. Therefore, the life cycle phase and the external conditions of estimation of the intellectual property's innovative capacity have the fundamental importance.

\section{Conclusion}

The need for assessment of the intellectual property's innovative capacity is justified by the following reasons. First of all, research and innovative organizations try to obtain exact projections of economic efficiencies of expected results on early phases of research projects. Second, they need to audit research and innovative organizations in order to reveal their hidden reserves and achieve their strategic goals. In that regard, development of an approach to assessment of the intellectual property's innovative capacity (the expediency of which is determined from the perspective of performance of research and innovative organizations) is important. The research suggests an approach, in terms of which the intellectual property's innovative capacity is represented as an integrated indicator of relationship between the 
defuzzificated combination of fuzzy components of its core and the defuzzificated combination of fuzzy risks. It is designated for application in management of research and innovative projects, as well as in research planning. Use of these methods focuses on improvement in the approach of assessment of the potential economic efficiency of intellectual property in their commercialization.

Assessment of the intellectual property's innovative capacity is based on approaches to assessment of applications' competitive rating, resources available to intellectual property on the basis of resource capacity and the balance of resources and costs, as well as assessment of the intellectual property's market value and generated income. Therefore, the developed method is universal and may be adapted to a particular line of business.

\section{Acknowledgements}

This research project was supported by the Russian Scientific Fund (RSF Project No. 14-18-00519).

\section{References}

Abernathy, W.J., \& Utterback, J.M. (1978). Patterns of Industrial Innovation. Technology Review 7, 40-47.

Abramov, V.I. (2012). Metodologiya otsenki innovatsionnogo potentsiala [Methodology for Assessing of Innovation Potential]. Extended abstract of Doctor's thesis. Sankt-Peterburg [in Russian].

Aletdinova, A.A. (2012). Metodologiya statisticheskogo issledovaniya innovatsionnogo potentsiala organizatsiy [Methodology of Statistical Research of Innovative Potential of Organizations]. Extended abstract of Doctor's thesis. Novosibirsk [in Russian].

Araujo, T., \& Mendes, R. Innovation Success and Structural Change: an Abstract Agent Based Study [Electronic resource]. http://arxiv.org - Retrieved from: http://arxiv.org/pdf/0709.2694.pdf

Artemova, M.M. (2006). Strategicheskoe upravlenie zatratami nauchno-proizvodstvennogo predpriyatiya pri realizatsii innovatsionnogo potentsiala [Strategic Cost Management of Research and Production Enterprise in the Implementation of the Innovative Capacity]. Extended abstract of candidate's thesis. Tyumen [in Russian].

Batkovskiy, A.M., Batkovskiy, M.A., \& Bozhko, V.P., et al (2014). Regulirovanie razvitiya bazovykh vysokotehnologichnykh otrasley [Regulation of Development of High-Tech Basic Industries]. Moscow: MESI [in Russian].

Dezhkina, I.P., \& Potasheva G.A. (2001). Innovatsionnyy potentsial hozyaystvennoy sistemy i ego otsenka (metody formirovaniya $i$ otsenki) [Innovative Potential of the Economic System and its Evaluation (Methods of Formation and Evaluation)]. Moscow: INFRA-M [in Russian].

Gayazova, D.V. (2012). Innovacionnyy potentsial ekonomicheskoy sistemy: otsenka i perspektiva razvitiya [Innovative Potential of the Economic System: Assessment and Prospects of Development]. Extended abstract of candidate's thesis. Irkutsk [in Russian].

Goncavles, S., Laguna, M.F., \& Iglesias, J.R. (2012). Why, when, and how fast innovation are adopted. [Electronic resource]. http://arxiv.org - Retrieved from: http://arxiv.org/pdf/1208.2589.pdf.

Henderson, R.M., \& Clark K.B. (1990). Architectural Innovation: The Reconfiguration of Existing Product Technologies and the Failure of Established Firms. Administrative Science Quarterly. 35, 9-30.

Kain, A., Kirschner, R., Gorbea, C., \& Kain, T., et al. (2010). Approach to Discover Innovation Potential by Means of Delta Application. The Materials of the 11th International Design Conference "DESIGN'10"( pp. 563-572). Dubrovnik: University of Zagreb.

Kurach, A.E. (2011). Formirovanie strategii razvitiya i upravleniya innovatsionnym potentsialom organizatsii [Forming a Strategy for Development and Management of Innovative Potential of Organization]. Extended abstract of candidate's thesis. Sankt-Peterburg [in Russian].

Matveykin, V.G., Dvoretskiy, S.I., \& Minko, L.V., et al. (2007). Innovatsionnyy potentsial: sovremennoe sostoyanie i perspektivy razvitiya [Innovation Potential: the Current State and Prospects of Development]. Moscow: Engineering Publishing, 1 [in Russian].

Mirzabekova, M.Ju. (2013). Klassifikatsiya innovatsionnogo potentsiala ekonomicheskoy sistemy [Classification of the Innovative Capacity of the Economic System]. Innovation management: theory, methodology, practice: $V$ mezhdunarodnaya nauchnoprakticheskaya konferentsiya (28 maya 2013 goda) - 5th International Scientific and Practical Conference. (pp. 28-34). Novosibirsk: OOO agency SIBPRINT [in Russian].

Neelanjan, S. Technology transfer and innovation. (2011). [Electronic resource]. http://cdedse.org - Retrieved from: http://www.cdedse. org/ws2011/papers/ Neelanjan.pdf.

Oluwoye, J., \& Lenard, D. (1999). Construction Innovation: An Overview of Innovative Construction Methods. CIB W55 \& W65 Joint Triennial Symposium, Cape Town.

Popova, A.I. (2009). Metody i mehanizmy upravleniya innovatsionnym potentsialom nauchno-issledovatelskoy organizatsii [Methods and Mechanisms for Managing the Innovative Potential of the Research Organization]. Extended abstract of candidate's thesis. Sankt-Peterburg [in Russian].

Ren, Y.-T., \& Yeo, K.-T. (2006). Research Challenges on Complex Product Systems (CoPS) Innovation. Journal of the Chinese Institute of Industrial Engineers. 6, 519-529.

Rogers, M. (2000). Understanding Innovative Firms: an Empirical Analysis of the GAPS. Melbourne Institute Working Paper, 8.

Rukovodstvo Oslo: 2-oe izd. [Oslo Manual: 2nd ed.]. (2010) Moscow: Centr issledovaniy statistiki i nauki. [in Russian].

Sen, N. Technology transfer and innovation [Electronic resource]. www.cdedse.org Retrieved from: http://www.cdedse.org/ws2011/ 
papers/Neelanjan.pdf

Schumpeter, J.A. (1994). Capitalism, Socialism and Democracy. London: Routledge.

Schumpeter, J.A. (1983). The Theory of Economic Development. New Brunswick: Transaction Publishers.

Shapovalova, T.A. (2010). Otsenka innovatsionnogo potentsiala organizatsii i puti povysheniya effektivnosti ego ispolzovaniya [Estimation of Innovative Potential of the Organization and Ways to Improve the Efficiency of its Use]. Extended abstract of candidate's thesis. Belgorod [in Russian].

Telnov, Yu.F., \& Kalachikhin, P.A. (2014). Innovatsionnyy potentsial rezultatov intellektualnoy deyatelnosti: metody, modeli i metodiki otsenki [Innovative Potential of Intellectual Activity: Methods, Models and Methods of Evaluation]. Saarbryukken: Lambert Academic Pablishing [in Russian].

Wang, S., \& Wan, C. (2014). Innovation, competition, diversification: a tree form dynamics of long-term development. [Electronic resource]. http://arxiv.org - Retrieved from: http://arxiv.org/pdf/1411.2167.pdf.

Zharikov, V.V., Zharikov, I.A., Odnolko, V.G., \& Evseychev, A.I. (2009). Upravlenie innovatsionnymi protsessami [Management of Innovative Processes]. Tambov: Tambov State Technical University Publishing [in Russian].

Zizlavsky, O. (2011). Factors of an Innovation Potential Development are Known, but not Always Mastered. Economics and Management, 16, 1019-1024. 